\title{
Anti-factor Xa levels in obese patients receiving enoxaparin for treatment and prophylaxis indications
}

This article was published in the following Dove Press journal:

Clinical Pharmacology:Advances and Applications

\author{
Linda Tahaineh' \\ Sahar M Edaily' \\ Shadi F Gharaibeh ${ }^{2}$ \\ 'Department of Clinical Pharmacy, \\ Faculty of Pharmacy, Jordan University \\ of Science and Technology (JUST), \\ Irbid, Jordan; ${ }^{2}$ Department of \\ Pharmaceutical Sciences, Faculty of \\ Pharmacy, Jerash University, Jerash, \\ Jordan
}

Objectives: To evaluate the degree of anticoagulation achieved with different enoxaparin dosing regimens used in obese and morbidly obese patients in a hospital setting in Jordan.

Methods: All obese adult patients who were prescribed enoxaparin for various indications were invited to participate in the study. The anti-factor Xa (anti-Xa) level was checked once after 4-6 hours of the third or fourth dose of enoxaparin (at steady state). Patients were followed daily to evaluate drug efficacy and safety through their hospital course.

Results: Enoxaparin daily dose used for prophylaxis indications ranged from 0.3 to $0.85 \mathrm{mg} / \mathrm{kg}$ and from 0.31 to $2.25 \mathrm{mg} / \mathrm{kg}$ in case of certain treatment indications. Most participants who received enoxaparin for treatment indications (76.9\%) were on capping dosing regimens, which was $<1 \mathrm{mg} / \mathrm{kg}$ twice daily. On the other hand, most patients $(88.5 \%)$ who received enoxaparin for prophylaxis indications were on a fixed $40 \mathrm{mg} / \mathrm{d}$ dose. Among the 52 patients who completed the study, 19 patients (36.5\%) had therapeutic anti-Xa levels. The results showed no statistically significant associations between regimens that were used and achieving therapeutic anti-Xa level ( $p>0.05$ ). No bleeding events or thrombocytopenia were noticed, and there was one case of recurrent thrombosis.

Conclusion: Enoxaparin dosing regimens that were used for obese patients varied based on prescribing physicians. Regardless of the regimen used, the majority of participants had nontherapeutic anti-Xa. Individualized dosing regimens based on anti-Xa levels are warranted for obese patients on enoxaparin.

Keywords: anti-factor $\mathrm{Xa}$, anticoagulation, enoxaparin, obesity

\section{Introduction}

Enoxaparin is a low molecular weight heparin used for prophylaxis and treatment of venous thromboembolism. ${ }^{1}$ The standard prophylactic dose of enoxaparin is $40 \mathrm{mg}$ daily or $30 \mathrm{mg}$ twice daily. On the other hand, the standard treatment dose of enoxaparin is $1 \mathrm{mg} / \mathrm{kg}$ twice daily or $1.5 \mathrm{mg} / \mathrm{kg}$ daily. ${ }^{2}$

Enoxaparin achieves anticoagulant effect by activating antithrombin. Routine laboratory monitoring for efficacy is not usually necessary. However, in special situations such as obesity, renal insufficiency, and pregnancy, laboratory monitoring may be required. The peak anti-factor $\mathrm{Xa}$ (anti-Xa) level is the recommended test for monitoring enoxaparin efficacy. Blood samples should be withdrawn about 3-5 hours after dose administration. The target peak anti-Xa level for prophylactic doses of enoxaparin is $0.2-0.5 \mathrm{IU} / \mathrm{mL}$. Target peak anti-Xa for the treatment doses of twice-daily enoxaparin is $0.6-1.0 \mathrm{IU} / \mathrm{mL}$ and $>1.0 \mathrm{IU} / \mathrm{mL}$ for once-daily dosing. ${ }^{3,4}$
Department of Clinical Pharmacy, Faculty of Pharmacy, Jordan University of Science and Technology, Irbid 22I I0, Jordan Tel +962 27201000 (ext 23436) Fax +962 27201075 Email tahaineh@just.edu.jo 
Obesity is a serious public health problem with a high prevalence globally. ${ }^{5}$ In Jordan, a study was conducted to investigate the prevalence of obesity and the change in obesity prevalence in the North of Jordan over 10 years. The study evaluated more than 1,000 participants aged 25 years and older. The results showed a high prevalence of obesity especially among women, where the age-standardized prevalence of obesity was $28.1 \%$ (95\% confidence interval: $23.4,32.8)$ for men and 53.1\% (95\% confidence interval: $49.3,57.0)$ for women. In addition, the results showed a significant increase in the prevalence of obesity for both men and women aged 60 years and older over a period of 10 years. ${ }^{6}$

Enoxaparin pharmacokinetic properties like absorption at the injection site and elimination half-life are predictable and well characterized in healthy nonobese individuals. ${ }^{3}$ However, in the case of obesity, pharmacokinetic parameters such as the rate of absorption, volume of distribution, and renal clearance may be affected. ${ }^{7,8}$ Several published papers evaluated enoxaparin dosing regimens used in the case of obese patients and found that standard enoxaparin doses in obese patients often did not result in therapeutic anti-Xa levels. ${ }^{9-12}$

The main objective of this study was to investigate enoxaparin dosing regimens used in obese and morbidly obese patients in a hospital setting in Jordan. Other study objectives were to assess the degree of anticoagulation achieved with enoxaparin dosing regimens used in obese and morbidly obese patients. Additionally, this study also investigated short-term health outcomes associated with enoxaparin dosing regimens used in obese and morbidly obese patients.

\section{Methods}

The study was conducted prospectively at King Abdullah University Hospital (KAUH) at the internal medicine ward, surgery ward, coronary care unit, intermediate cardiac care unit, and intensive care unit. All adult patients (18 years and older) who were obese or morbidly obese with body mass index $(\mathrm{BMI}) \geq 30 \mathrm{~kg} / \mathrm{m}^{2}$ not currently participating in a clinical study and being prescribed enoxaparin for prophylactic or treatment purposes were invited to participate in this study. The World Health Organization classification of BMI was applied: underweight (BMI $<18.5 \mathrm{~kg} / \mathrm{m}^{2}$ ), normal (BMI $18.5-24.9 \mathrm{~kg} / \mathrm{m}^{2}$ ), overweight (BMI $\geq 25 \mathrm{~kg} / \mathrm{m}^{2}$ ), and obese $\left(\mathrm{BMI} \geq 30 \mathrm{~kg} / \mathrm{m}^{2}\right) .^{5}$

\section{Compliance with ethical standards}

The study protocol was approved by the Jordan University of Science and Technology Institutional Review Board committee (Research Number 16/92/2015) on December 15, 2015.
Written informed consent was obtained from all individual participants included in the study.

The study excluded patients receiving other anticoagulants; those suffering from a known coagulation disorder, active bleeding or bleeding disorder, serious liver or kidney diseases, or thrombocytopenia; those having had a stroke, surgery, or trauma within 14 days; or those who were pregnant or breast-feeding.

Data were collected through patient interviews and medical record reviews. Data included medical and surgical histories, smoking status, physical activity, diet, past and current medications, and enoxaparin dosing regimen. Through the hospital course, patients were followed daily to evaluate efficacy and safety. Clinical assessment of venous thromboembolism symptoms, major and nonmajor bleeding, and thrombocytopenia were assessed. A complete blood count and the anti-Xa level were measured for each patient during their hospital stay. An anti-Xa colorimetric assay test was done in the KAUH hematology laboratory. Ideally, the peak anti-Xa level should be measured after 4-6 hours of the first dose and each dose of enoxaparin administration through the hospital stay period. The anti-Xa level was checked once after 4-6 hours of the third or fourth dose (at steady state). ${ }^{13}$ The target peak anti-Xa level for prophylactic doses of enoxaparin is $0.2-0.5 \mathrm{IU} / \mathrm{mL}$. Target peak anti-Xa for the treatment doses of twice-daily enoxaparin is $0.6-1.0$ $\mathrm{IU} / \mathrm{mL}$ and $>1.0 \mathrm{IU} / \mathrm{mL}$ for once-daily dosing. ${ }^{3,4}$ Two blood samples from each participant after 4-6 hours of the third or fourth dose of enoxaparin were drawn by a nurse. One was placed in an EDTA tube and the other in a citrated tube for complete blood count and anti-Xa measurement, respectively. Samples were refrigerated until the assay tests were done. Anti-Xa colorimetric assay test was done at KAUH Hematology Laboratory. Liquid anti-Xa kits contained 2 reagents; reagent 1 that contained chromogenic substrate and reagent 2 that contained bovine factor Xa. Both reagents were used for quantitative determination of anti-Xa activity.

Data collection extended from March 2016 to November 2016.

\section{Sample size and study power}

Based on previous studies ${ }^{9,12}$ a sample size of at least 50 patients was expected to provide $80 \%$ power where $\alpha$ (2-tailed) equals 0.05 .

\section{Data analysis and statistics}

Data were analyzed using the Statistical Package for Social Science (SPSS version 16; SPSS Inc., Chicago, IL, USA). 
Patients' demographics, relevant clinical characteristics at baseline, enoxaparin dosing regimens used in KAUH, anti-Xa levels, and percentage of patients that reached therapeutic or nontherapeutic levels were described using frequency distribution. In addition, health-related outcome and clinical assessment of safety and efficacy of enoxaparin dosing regimens were described using frequency distribution. A Fisher's exact test was used to compare the effect of different dosing regimens of enoxaparin on anti-Xa levels and to evaluate the association between different patients' demographic characteristics such as age, gender, and anti-Xa levels. Fisher's exact test was used in 2 by 2 tables because of the small sample size. Additionally, a Fisher's exact test was used to evaluate the association between patients' past medical history and anti-Xa levels. Analysis of covariance was used to study the effect of gender on anti-Xa levels while controlling the effect of the enoxaparin dose. A $p$-value $<0.05$ was considered statistically significant.

\section{Results}

Through the study duration, a total of 419 adult obese patients $\left(B M I \geq 30 \mathrm{~kg} / \mathrm{m}^{2}\right.$ ) were prescribed enoxaparin. Three hundred thirty three patients were excluded. Reasons for exclusions included chronic kidney disease, recent trauma, recent surgery, and others. A total of 86 patients met the inclusion criteria and signed the informed consent; however, 52 patients completed the study. Thirty four patients dropped out. The flow diagram of the study is shown in Figure 1.

The participants' ages ranged from 18 to 88 years. Actual body weight ranged from 68 to $201 \mathrm{~kg}$, and mean weight was $101.9 \pm 23.3 \mathrm{~kg}$. The study found that $51.2 \%(\mathrm{n}=44)$ of the study population were obese and $48.8 \%(n=42)$ were morbidly obese. BMI ranged from 30.02 to $70.38 \mathrm{~kg} / \mathrm{m}^{2}$; mean BMI was $37.00 \pm 8.48 \mathrm{~kg} / \mathrm{m}^{2}$, and median BMI was $34.74 \mathrm{~kg} / \mathrm{m}^{2}$. Patients' baseline demographics and clinical characteristics are listed in Table 1.

During the hospital course, different enoxaparin dosing regimens were used for treatment and prophylaxis indications. The results showed that $76.9 \%$ of patients who were on enoxaparin for treatment indications received a capped treatment dose, which is $<1 \mathrm{mg} / \mathrm{kg}$ twice daily $(\mathrm{n}=20)$. On the other hand, $88.5 \%$ of patients who were on enoxaparin for prophylaxis indications received a fixed prophylactic dose of $40 \mathrm{mg} / \mathrm{d}(\mathrm{n}=23)$.

Anti-Xa levels were measured once for each patient during the hospital course. The mean anti-Xa level for treatment group patients was $0.48 \pm 0.33 \mathrm{IU} / \mathrm{mL}$, and the mean anti-Xa level for prophylactic group was $0.22 \pm 0.26 \mathrm{IU} / \mathrm{mL}$.
Among the 52 patients, 19 patients $(36.5 \%)$ had therapeutic anti-Xa level and 33 patients $(63.5 \%)$ had nontherapeutic anti-Xa level. Table 2 lists the effect of enoxaparin dosing regimens on anti-Xa levels. The results showed no statistically significant correlation between dose regimens (with and without capping) that were used and achieving therapeutic anti-Xa level $(p>0.05)$. Most nontherapeutic anti-Xa levels were subtherapeutic except for 2 patients that were supratherapeutic. In addition, Table 3 shows the effect of enoxaparin dosing regimens on anti-Xa levels in morbidly obese patients.

Figure 2 shows anti-Xa levels for patients receiving different treatment and prophylaxis daily doses of enoxaparin.

Correlation analysis using Fisher's exact test for categorical variables showed significant relationship between patients' gender and anti-Xa levels $(p<0.05)$. However, no significant relationships between other patients' demographic characteristics and past medical history and anti-Xa levels ( $p>0.05)$ were found. Furthermore, analysis of covariance test results showed a significant effect of gender on anti-Xa levels after controlling the effect of the enoxaparin dose when enoxaparin was used for prophylaxis indications $(p=0.03)$. Figure 3 shows anti-Xa levels for female and male patients receiving different prophylaxis daily doses of enoxaparin. Females were more responsive to enoxaparin compared to males for prophylaxis indications only.

During the hospital course, patients also were followed daily to evaluate efficacy and safety of enoxaparin dosing regimens. Clinical assessment of venous thromboembolism symptoms, major and nonmajor bleeding, and thrombocytopenia were assessed. No bleeding events or thrombocytopenia were noticed, but there was 1 case of recurrent thrombosis on the third day of hospitalization (after the fifth treatment dose of enoxaparin) for a patient with actual body weight $=116 \mathrm{~kg}$ and $\mathrm{BMI}=45.3 \mathrm{~kg} / \mathrm{m}^{2}$, who was on enoxaparin capped treatment dose of $100 \mathrm{mg}$ twice daily and had a nontherapeutic anti-Xa level.

\section{Discussion}

This was the first prospective study in Jordan to evaluate enoxaparin dosing regimens used in obese and morbidly obese patients; it covered patients with different enoxaparin indications and different enoxaparin dosing regimens.

The enoxaparin dosing regimens observed in this study were reflective of those seen in other studies..$^{9-11}$ In the present study, the majority of participants whether prescribed enoxaparin for prophylaxis or treatment indications and whether they were prescribed capping or noncapping dosing 


\section{Assessed for eligibility}

419 adult obese patients (body mass index $\geq 30 \mathrm{~kg} / \mathrm{m}^{2}$ ) on enoxaparin treatment or prophylactic doses admitted to $\mathrm{KAUH}$

333 Patients did not meet the inclusion criteria:

- 72 Patients had recent surgery

- 63 Patients had chronic kidney disease

- 52 Patients underwent cardiac catheterization before the third dose

- 40 Patients had recent stroke

- 26 Patients refused to participate in the study

- 25 Patients were on warfarin

- 17 Patients had recent trauma

- 13 Patients were unconscious or disoriented

- 12 Patients were on enoxaparin but it was discontinued before third dose

- 8 Patients received only stat dose of enoxaparin

- 2 Patients had liver disease

- 2 Pregnant women

- 1 Breastfeeding woman
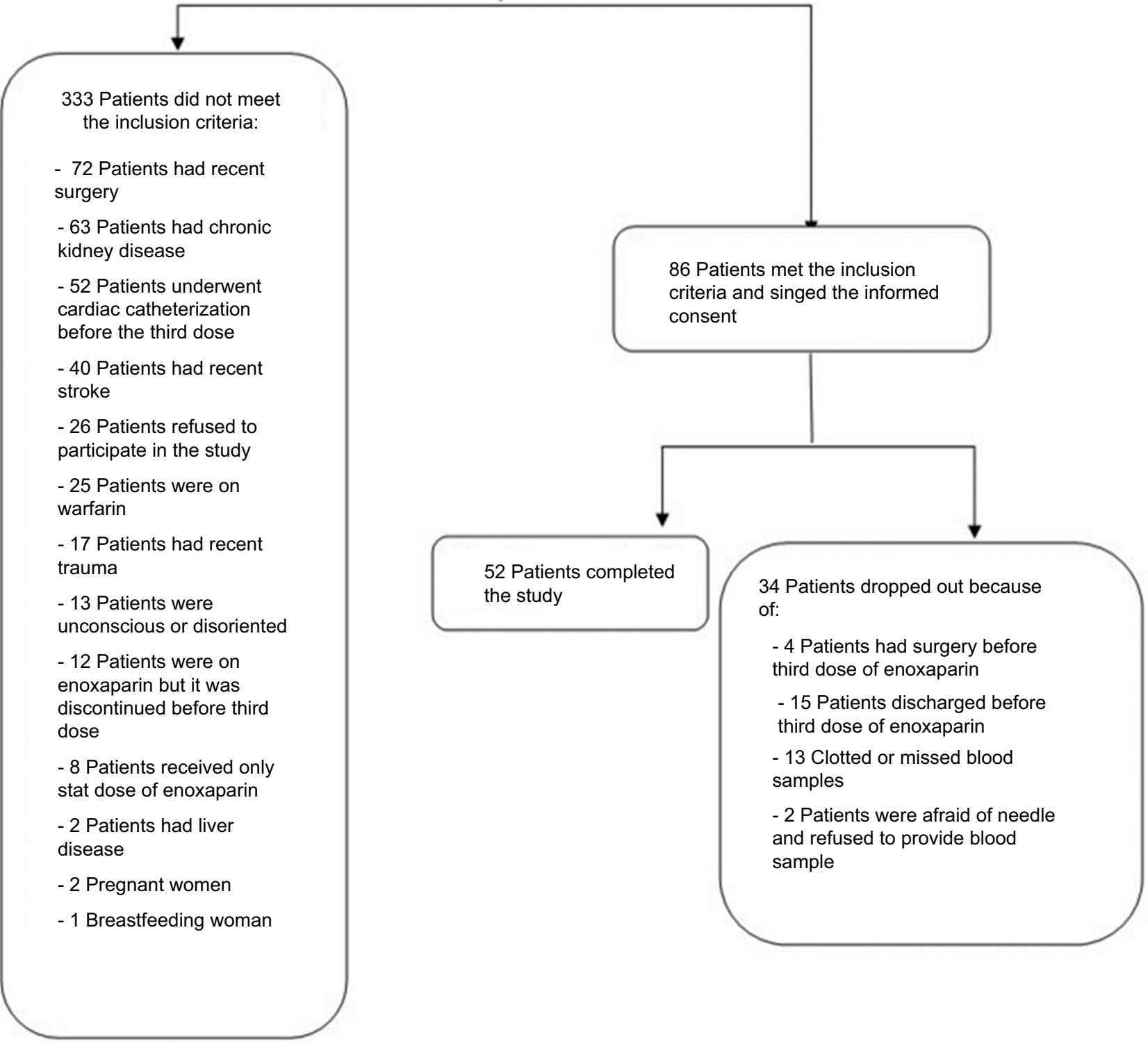

Figure I Flow diagram for this study population. Abbreviation: KAUH, King Abdullah University Hospital.

regimens did not achieve the target therapeutic anti-Xa level. The results of the present study indicate that other factors besides patients' weight affect anti-Xa levels. This indication is supported by previously published studies. ${ }^{9}, 14$ For example, a prospective study was conducted to evaluate factors affecting anti-Xa levels in a general surgical intensive care unit population. The study concluded that females and patients with lower creatinine clearance have higher anti-Xa activity. ${ }^{14}$ In addition, a study was conducted to investigate factors that may affect the pharmacokinetics of subcutaneous 
Table I Patient demographics and clinical characteristics at baseline $(\mathrm{N}=86)$.

\begin{tabular}{ll}
\hline Patient characteristics & $\mathbf{n}(\%)$ \\
\hline Gender & $39(45.3)$ \\
Female & $47(54.7)$ \\
Male & \\
Age (years) & $50.8 \pm 17.2$ \\
Mean \pm SD & 53 \\
Median & $18-88$ \\
Range & \\
Smoking status & $15(17.4)$ \\
Current smoker & $14(16.3)$ \\
Former smoker & $32(37.2)$ \\
Non-smoker & $24(27.9)$ \\
Passive smoking & \\
Water pipe use & $68(79.1)$ \\
None & $12(14.0)$ \\
Current smoker & $6(7.0)$ \\
Former smoker & \\
BMl (kg/m²) & $44(51.2)$ \\
Obese & $42(48.8)$ \\
Morbidly obese & \\
Past medical history & $42(48.8)$ \\
Diabetes mellitus & $45(52.3)$ \\
Hypertension & $7(8.1)$ \\
Cancer & $38(44.2)$ \\
Taking medications increasing risk of bleeding & \\
\hline Abrevitions BMI, body mass & \\
\hline
\end{tabular}

Abbreviations: BMI, body mass index; SD, standard deviation.

enoxaparin in trauma patients. Factors studied included BMI, abdominal wall thickness, and fluid balance. The results showed that increased BMI and abdominal wall thickness correlated significantly with a higher dose required to achieve a therapeutic anti-Xa. However, fluid balance did not show a significant correlation. ${ }^{9}$

Previously published studies did not agree on specific enoxaparin dosing regimens that will result in therapeutic anti-Xa levels for prophylaxis or treatment indications in obese patients..$^{911,14-17}$ For example, a prospective study sequentially assigned medically ill and extremely obese patients who were prescribed enoxaparin for prophylaxis indications into 3 groups. The first group received a fixed dose of enoxaparin of $40 \mathrm{mg} / \mathrm{d}$, the second group received $0.4 \mathrm{mg} / \mathrm{kg} / \mathrm{d}$, and the third group received high-dose enoxaparin of $0.5 \mathrm{mg} / \mathrm{kg} / \mathrm{d}$. Peak anti-Xa levels were measured 4-6 hours after the enoxaparin daily dose. The results showed that patients on high-dose, $0.5 \mathrm{mg} / \mathrm{kg} / \mathrm{d}$, enoxaparin achieved therapeutic anti-Xa levels more frequently than patients on fixed dose of $40 \mathrm{mg} / \mathrm{d}$ or $0.4 \mathrm{mg} / \mathrm{kg} / \mathrm{d}(p<0.05) .{ }^{15}$ Another prospective study enrolled obese and nonobese patients receiving $30 \mathrm{mg}$ enoxaparin twice daily for venous thromboembolism prophylaxis. The study measured trough
Table 2 The effect of enoxaparin dosing regimens on anti-Xa levels

\begin{tabular}{|c|c|c|c|}
\hline \multirow[t]{2}{*}{ Anti-Xa level } & \multicolumn{2}{|c|}{$\begin{array}{l}\text { Enoxaparin dosing regimens } \\
\text { for treatment and prophylaxis } \\
\text { indications }(\mathrm{N}=52)\end{array}$} & \multirow[t]{2}{*}{$P$-value*t } \\
\hline & $\begin{array}{l}\text { With capping* } \\
\text { n (\%) }\end{array}$ & $\begin{array}{l}\text { Without capping } \\
\text { n (\%) }\end{array}$ & \\
\hline Therapeutic & $16(37.2)$ & $3(33.3)$ & 0.439 \\
\hline Nontherapeutic & $27(62.8)$ & $6(66.7)$ & \\
\hline \multirow[t]{2}{*}{ Anti-Xa level } & \multicolumn{2}{|c|}{$\begin{array}{l}\text { Enoxaparin dosing regimens for } \\
\text { treatment indications }(\mathrm{N}=26)\end{array}$} & $P$-value** \\
\hline & $\begin{array}{l}\text { With capping* } \\
\text { n (\%) }\end{array}$ & $\begin{array}{l}\text { Without capping } \\
\text { n (\%) }\end{array}$ & \\
\hline Therapeutic & $6(30)$ & $2(33.3)$ & 0.439 \\
\hline Nontherapeutic & $14(70)$ & $4(66.7)$ & \\
\hline \multirow[t]{4}{*}{ Anti-Xa level } & \multicolumn{2}{|c|}{$\begin{array}{l}\text { Enoxaparin dosing regimens for } \\
\text { prophylaxis indications }(\mathrm{N}=26)\end{array}$} & $P$-value** \\
\hline & 40 mg q & $>40 \mathrm{mg} \mathrm{q}$ & \\
\hline & 24 hours & 24 hours & \\
\hline & n (\%) & n (\%) & \\
\hline Therapeutic & $10(43.5)$ & I (33.3) & 0.738 \\
\hline \multirow[t]{4}{*}{ Anti-Xa level } & \multicolumn{2}{|c|}{$\begin{array}{l}\text { Enoxaparin dosing regimens for } \\
\text { prophylaxis indications }(\mathrm{N}=\mathbf{2 6})\end{array}$} & $P$-value** \\
\hline & 40 mg q & $>40 \mathrm{mg} \mathrm{q}$ & \\
\hline & 24 hours & 24 hours & \\
\hline & n (\%) & n (\%) & \\
\hline Nontherapeutic & $13(56.5)$ & $2(66.7)$ & 0.738 \\
\hline
\end{tabular}

Notes: The target peak anti- $X_{a}$ level for prophylactic doses of enoxaparin is $(0.2-0.5) \mathrm{IU} / \mathrm{mL}$. The target peak anti-Xa level for treatment doses for twice-daily enoxaparin is $(0.6-1.0) \mathrm{IU} / \mathrm{mL}$ and $>1.0 \mathrm{IU} / \mathrm{mL}$ for once-daily dosing. ${ }^{*}$ Capping means enoxaparin treatment dose $<\mathrm{l} \mathrm{mg/kg} \mathrm{twice} \mathrm{daily,} \mathrm{or} \mathrm{enoxaparin} \mathrm{prophylactic} \mathrm{dose} \mathrm{of}$ $40 \mathrm{mg} / \mathrm{d}$. **Fisher's exact test.

Abbreviation: Anti-Xa, anti-factor $\mathrm{Xa}$.

Table 3 The effect of enoxaparin dosing regimen on anti-Xa level for morbidly obese patient* $(\mathrm{N}=23)$

\begin{tabular}{|c|c|c|c|}
\hline \multirow[t]{2}{*}{ Anti-Xa level } & \multicolumn{2}{|c|}{$\begin{array}{l}\text { Enoxaparin dosing regimens } \\
\text { for treatment and prophylactic } \\
\text { indications }\end{array}$} & \multirow[t]{2}{*}{$P$-value**** } \\
\hline & $\begin{array}{l}\text { With capping** } \\
\text { n (\%) }\end{array}$ & $\begin{array}{l}\text { Without capping } \\
\text { n (\%) }\end{array}$ & \\
\hline Therapeutic & $2(25)$ & $8(53.3)$ & 0.439 \\
\hline Nontherapeutic & $6(75)$ & $7(46.7)$ & \\
\hline
\end{tabular}

Notes: The target peak anti- $X_{a}$ level for prophylactic doses of enoxaparin is $(0.2-0.5) \mathrm{IU} / \mathrm{mL}$. The target peak anti-Xa level for treatment doses for twice-daily enoxaparin is $(0.6-1.0) \mathrm{IU} / \mathrm{mL}$ and $>1.0 \mathrm{IU} / \mathrm{mL}$ for once-daily dosing. *Morbidly obese $=\mathrm{BMI} \geq 40 \mathrm{~kg} / \mathrm{m}^{2}$. ${ }^{* *}$ Capping means enoxaparin treatment dose $<1 \mathrm{mg} / \mathrm{kg}$ twice daily, or enoxaparin prophylactic dose of $40 \mathrm{mg} / \mathrm{d}$. ****isher's exact test.

Abbreviations: Anti- $\mathrm{X}$, anti-factor $\mathrm{Xa}$; BMl, body mass index.

anti-Xa levels 30 minutes before the fourth enoxaparin dose and considered anti-Xa level of $<0.1 \mathrm{IU} / \mathrm{mL}$ subtherapeutic. The results showed that regardless of BMI, the enoxaparin dose of $30 \mathrm{mg}$ twice daily is insufficient. ${ }^{9}$

A prospective study evaluated two enoxaparin prophylaxis regimens used for patients undergoing laparoscopic 


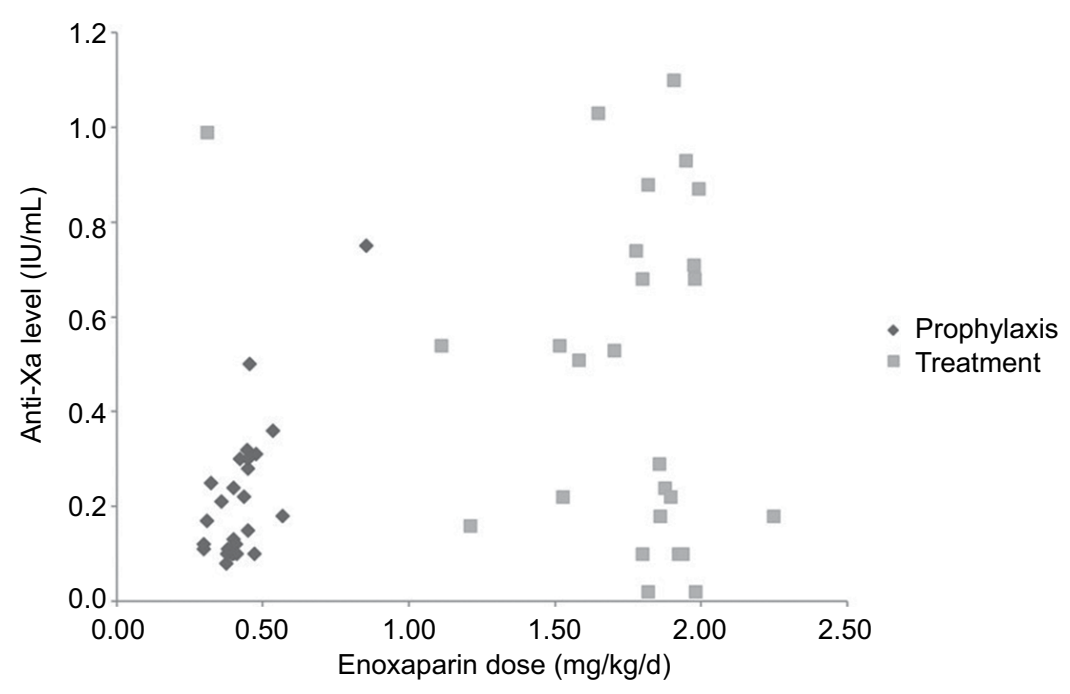

Figure 2 Anti-Xa levels for patients receiving different treatment and prophylaxis daily doses of enoxaparin.

Abbreviation: Anti-Xa, anti-factor Xa.

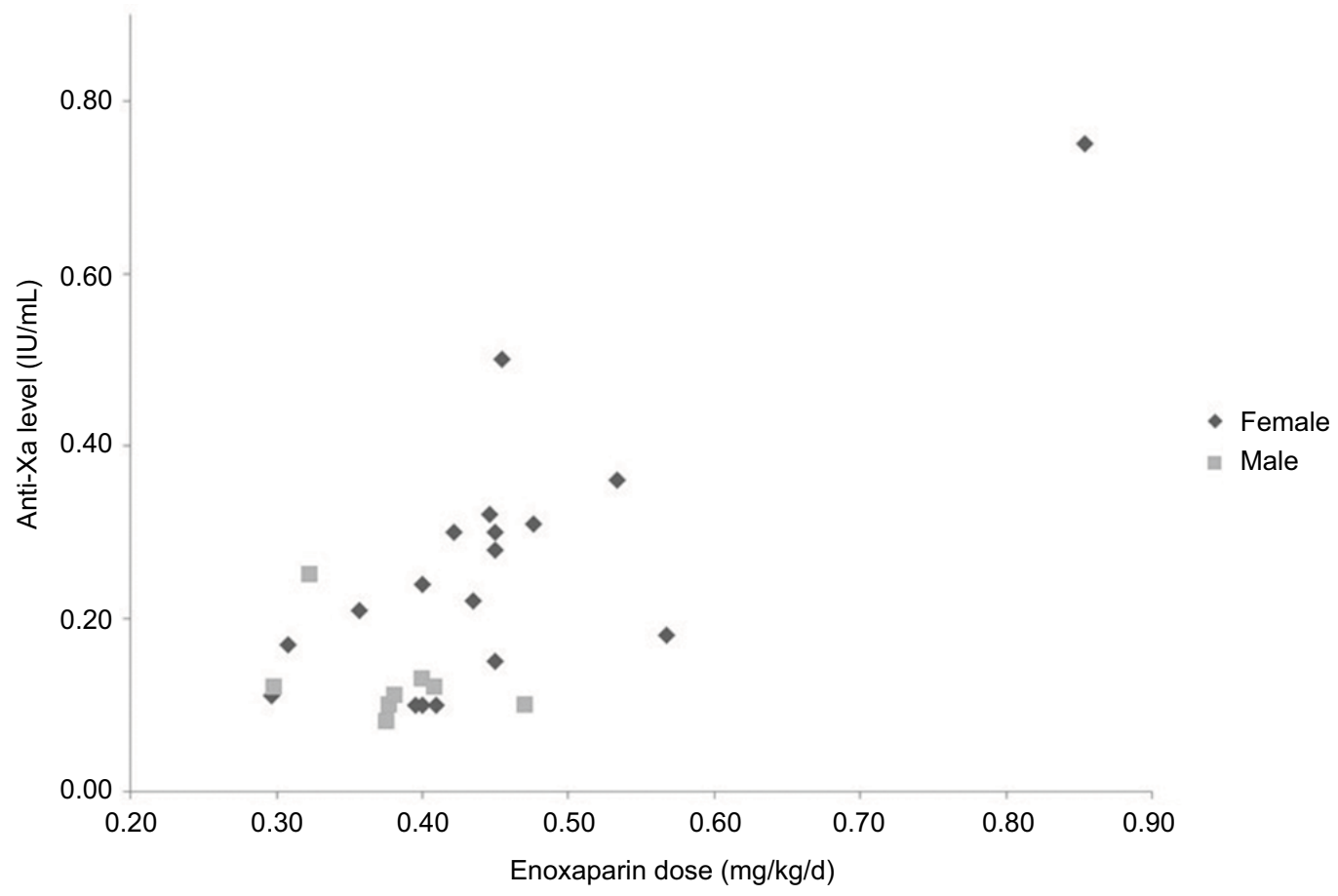

Figure 3 Anti-Xa levels for females and males receiving different prophylaxis daily doses of enoxaparin.

Abbreviation: Anti-Xa, anti-factor $X a$.

bariatric surgery. The first regimen was $40 \mathrm{mg}$ twice daily and the second regimen was $60 \mathrm{mg}$ twice daily. Peak anti-Xa levels were measured 4 hours after enoxaparin administration. After the third dose, the $60 \mathrm{mg}$ twice-daily regimen was superior in achieving therapeutic enoxaparin levels compared to the $40 \mathrm{mg}$ twice-daily regimen. However, $57 \%$ of the 60 mg twice-daily regimen anti-Xa levels were supratherapeutic compared to $0 \%$ of the $40 \mathrm{mg}$ twice-daily regimen. ${ }^{16}$
On the other hand, a retrospective study reviewed the dosing and monitoring of therapeutic enoxaparin in 3 high-risk patient populations including patients weighing more than $150 \mathrm{~kg}$. Patients receiving enoxaparin for prophylaxis were excluded from the study. Peak anti-Xa levels drawn 3-5 hours after enoxaparin administration were used for analysis. The results showed that obese patients achieved therapeutic antiXa levels with doses lower than $1 \mathrm{mg} / \mathrm{kg} /$ dose.${ }^{17}$ 
A retrospective review evaluated an inpatient protocol that implemented a reduced enoxaparin dose of $0.75 \mathrm{mg} / \mathrm{kg}$ / dose for morbidly obese patients. Peak anti-Xa levels were assessed 4 hours after the fourth dose. The study evaluated 31 patients, and of those, 24 patients $(77 \%)$ achieved therapeutic anti-Xa during their hospitalization. ${ }^{18}$

In the present study, the majority of patients had nontherapeutic anti-Xa levels. This finding can be alarming knowing the fact that most nontherapeutic anti-Xa readings were subtherapeutic. Subtherapeutic anti-Xa levels will put patients at risk of treatment failure or thromboembolism. The present authors recommend individualized enoxaparin dosing regimens and dosing adjustment based on anti-Xa levels in order to achieve therapeutic anti-Xa levels, optimize efficacy, and decrease side effects.

A significant correlation was found between the female gender and patients who achieved therapeutic anti-Xa in the case of prophylaxis indication only. This result was in accordance with the results found by Vincent et al. ${ }^{14}$ Vincent et al ${ }^{14}$ studied 36 patients who received $30 \mathrm{mg}$ enoxaparin twice daily for thromboembolism prophylaxis. The results showed that the female gender was associated with higher anti-Xa activity. ${ }^{14}$

The results of this study should be considered within the context of its limitations. The first limitation was the small sample size. The second limitation was that the study was conducted in a single hospital. Thus, the results might not be generalized to other settings. In addition, due to a budget limitation, a single anti-Xa level was measured instead of measuring multiple anti-Xa levels after each dose of enoxaparin. Also, the study lacked a control group of nonobese patients using the similar dosing regimens.

\section{Conclusion}

In conclusion, the dosing regimens of enoxaparin used for obese patients varied based on prescribing physicians. Some patients were prescribed the capping dosing regimens and some were prescribed higher or noncapping dosing regimens.

The majority of participants had nontherapeutic anti-Xa levels; however, there was no significant association between regimens that were used and achieving therapeutic anti-Xa levels. In addition, no significant association was found between the incidence of side effects and different dosing regimens.

The present authors recommend anti-Xa monitoring for obese and morbidly obese patients on prophylactic or treatment indications of enoxaparin and recommend dose adjustment of enoxaparin according to anti-Xa levels to achieve the desired therapeutic outcomes and to avoid the undesired health outcomes.

The present authors recommend more studies on enoxaparin dosing regimens used for obese and morbidly obese patients enrolling larger number of patients and covering other clinical settings.

\section{Acknowledgments}

The authors would like to acknowledge Amal AlBadawi, $\mathrm{RPh}, \mathrm{Msc}$, and Batool Shhabat, RPh, Msc, for their assistance and help.

The results of this paper were presented in part in the 13th Congress of the European Association for Clinical Pharmacotherapy and Therapeutics; 2017 June 24-27; Prague, Czech Republic. The abstract will be published in part in the proceedings of the conference in the journal Clinical Therapeutics.

This study was supported by a grant from the Deanship of Scientific Research, Jordan University of Science and Technology, Irbid, Jordan.

\section{Disclosure}

The authors report no conflicts of interest in this work.

\section{References}

1. Garcia DA, Baglin TP, Weitz JI, Samama MM. Parenteral anticoagulants: antithrombotic therapy and prevention of thrombosis, 9th ed: American College of Chest Physicians evidence-based clinical practice guidelines. Chest. 2012;141(Suppl 2):e24S-e43S.

2. DiPiro JT, Talbert RL, Yee GC, et al. Pharmacotherapy: A Pathophysiologic Approach. 9th ed. New York, NY: Mcgraw Hill Education; 2014.

3. Hirsh J, Bauer KA, Donati MB, Gould M, Samama MM, Weitz JI. Parenteral anticoagulants: American College of Chest Physicians evidencebased clinical practice guidelines (8th edition). Chest. 2008;133(Suppl 6):141S-159S

4. Wei MY, Ward SM. The anti-factor Xa range for low molecular weight heparin thromboprophylaxis. Hematol Rep. 2015;7(4):5844.

5. World Health Organization. Obesity: Preventing and Managing the Global Epidemic. Report of a WHO Consultation. WHO Technical Report Series 894. Geneva: World Health Organization; 2000.

6. Khader Y, Batieha A, Ajlouni H, El-Khateeb M, Ajlouni K. Obesity in Jordan: prevalence, associated factors, comorbidities, and change in prevalence over ten years. Metab Syndr Relat Disord. 2008;6(2):113-120.

7. Hanley MJ, Abernethy DR, Greenblatt DJ. Effect of obesity on the pharmacokinetics of drugs in humans. Clin Pharmacokinet. 2010;49(2):71-87.

8. Egan G, Ensom MH. Measuring anti-factor xa activity to monitor low-molecular-weight heparin in obesity: a critical review. Can J Hosp Pharm. 2015;68(1):33-47.

9. Rostas JW, Brevard SB, Ahmed N, et al. Standard dosing of enoxaparin for venous thromboembolism prophylaxis is not sufficient for most patients within a trauma intensive care unit. Am Surg. 2015;81(9) 889-892. 
10. Stephenson ML, Serra AE, Neeper JM, Caballero DC, McNulty J. A randomized controlled trial of differing doses of postcesarean enoxaparin thromboprophylaxis in obese women. $J$ Perinatol. 2016;36(2): 95-99.

11. Thompson-Moore NR, Wanat MA, Putney DR, Liebl PH, Chandler WL, Muntz JE. Evaluation and pharmacokinetics of treatment dose enoxaparin in hospitalized patients with morbid obesity. Clin Appl Thromb Hemost. 2015;21(6):513-520.

12. Deal EN, Hollands JM, Riney JN, Skrupky LP, Smith JR, Reichley RM. Evaluation of therapeutic anticoagulation with enoxaparin and associated anti-Xa monitoring in patients with morbid obesity: a case series. J Thromb Thrombolysis. 2011;32(2):188-194.

13. Ludwig KP, Simons HJ, Mone M, Barton RG, Kimball EJ. Implementation of an enoxaparin protocol for venous thromboembolism prophylaxis in obese surgical intensive care unit patients. Ann Pharmacother. 2011;45(11):1356-1362.
14. Vincent PD, Albert M, Champagne MC, et al. Factors influencing enoxaparin anti-Xa activity in surgical critically ill patients. J Crit Care. 2011;26(4):347-351.

15. Freeman A, Horner T, Pendleton RC, Rondina MT. Prospective comparison of three enoxaparin dosing regimens to achieve target anti-factor Xa levels in hospitalized, medically ill patients with extreme obesity. Am J Hematol. 2012;87(7):740-743.

16. Simone EP, Madan AK, Tichansky DS, Kuhl DA, Lee MD. Comparison of two low-molecular-weight heparin dosing regimens for patients undergoing laparoscopic bariatric surgery. Surg Endosc. 2008;22(11):2392-2395.

17. Sacha GL, Greenlee KM, Ketz JM. The use of anti-factor Xa monitoring in a selection of patients receiving enoxaparin at a large academic medical center. J Thromb Thrombolysis. 2016;42(4):479-485.

18. Lalama JT, Feeny ME, Vandiver JW, Beavers KD, Walter LN, McClintic JR. Assessing an enoxaparin dosing protocol in morbidly obese patients. J Thromb Thrombolysis. 2015;39(4):516-521.
Clinical Pharmacology: Advances and Applications

\section{Publish your work in this journal}

Clinical Pharmacology: Advances and Applications is an international, peer-reviewed, open access journal publishing original research, reports, reviews and commentaries on all areas of drug experience in humans. The manuscript management system is completely online and includes a very quick and fair peer-review system, which is all easy to use.

\section{Dovepress}

Visit http://www.dovepress.com/testimonials.php to read real quotes from published authors. 